\title{
Sensitivity analyses
}

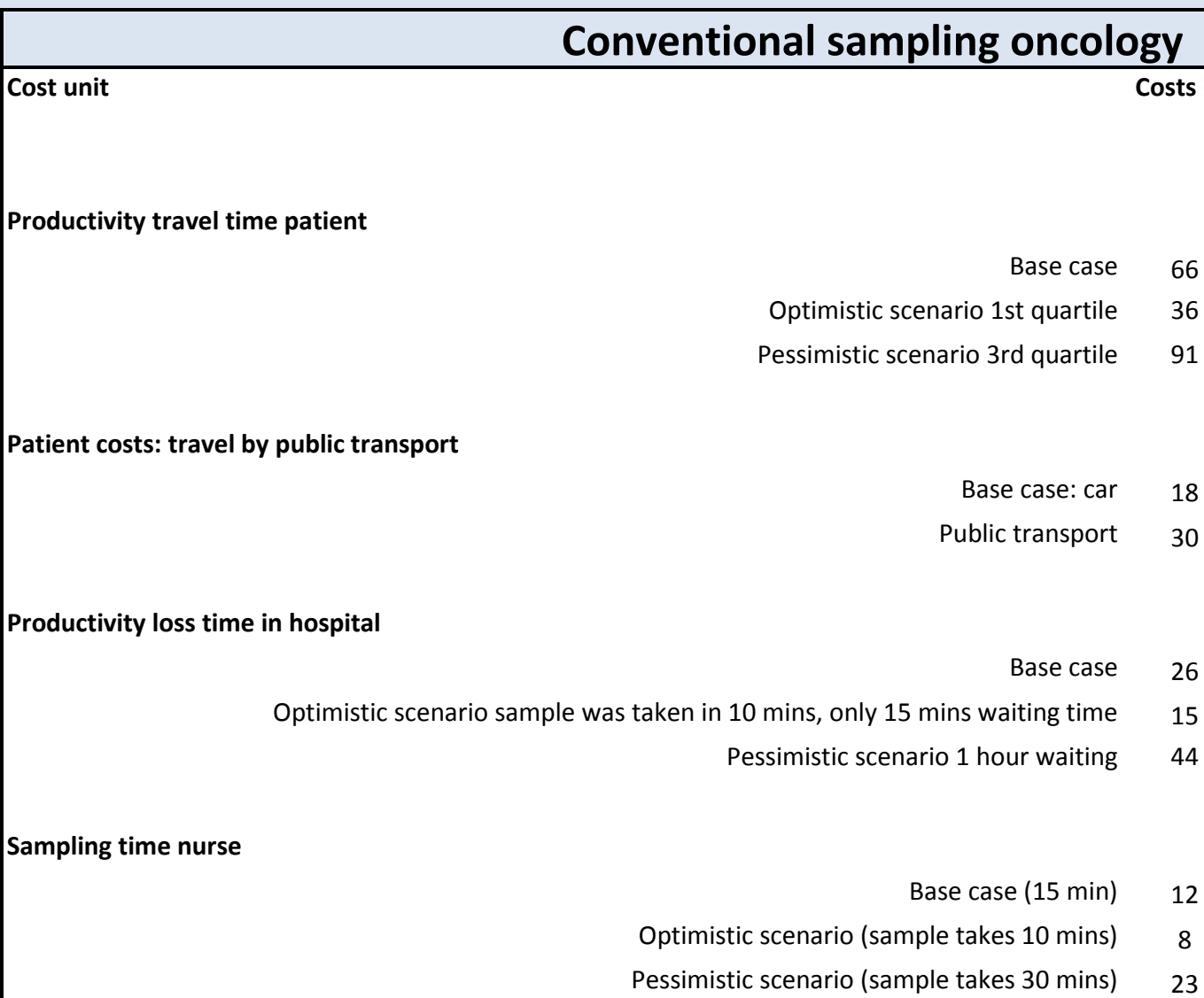

Costs of the lab analysis

$\begin{array}{rc}\text { Base case } & 50 \\ \text { CTG tarief } & 27 \\ \text { Twice base case } & 100\end{array}$

Costs related to review by pharmacist

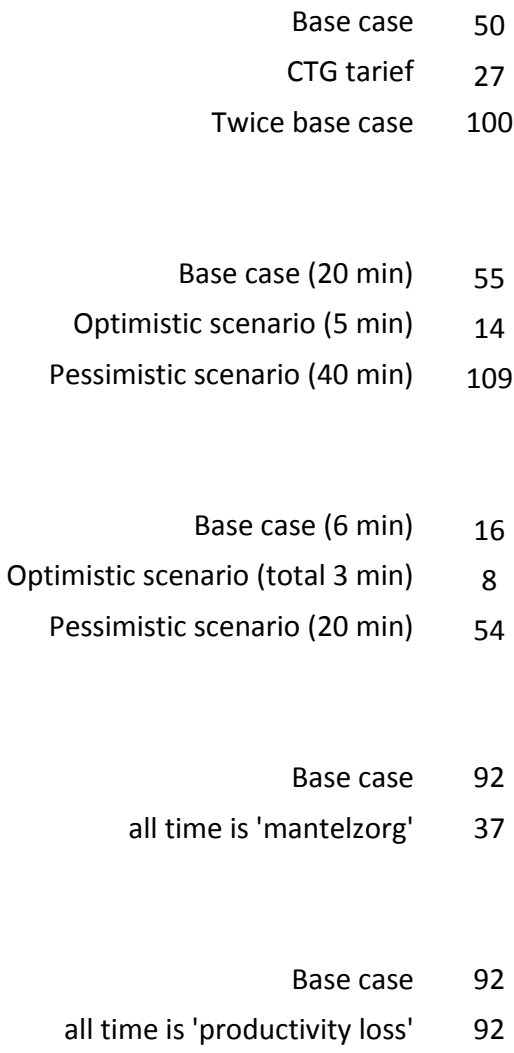

all time is 'productivity loss' $\quad 92$ 


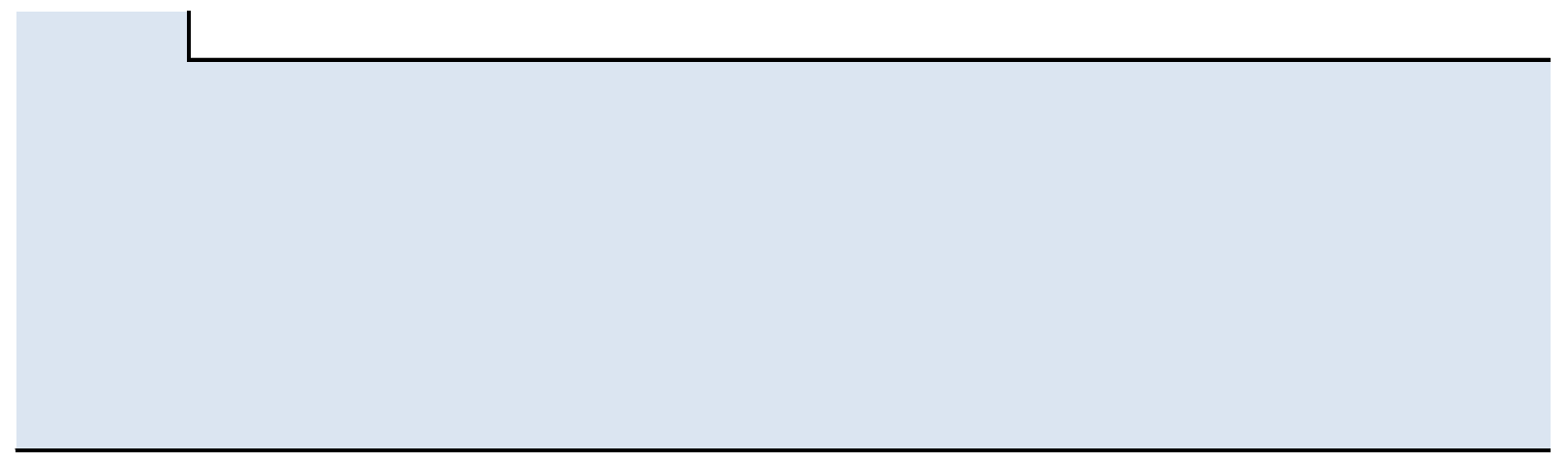




\section{Sensitivity analyses}

\begin{tabular}{|c|c|c|c|c|}
\hline & & \multicolumn{3}{|c|}{ DBS home sampling oncology } \\
\hline Total cost & Difference with base case & & Costs $(€)$ & Total cost \\
\hline 277 & NA & & & \\
\hline 247 & -30 & & & \\
\hline 302 & 25 & & & \\
\hline 277 & NA & & & \\
\hline 289 & 12 & & & \\
\hline 277 & NA & & & \\
\hline 265 & -12 & & & \\
\hline 294 & 17 & & & \\
\hline & & Sampling time parent & & \\
\hline 277 & NA & Base case (10 min) & 2 & 158 \\
\hline 273 & -4 & Optimistic scenario (5 min) & 1 & 157 \\
\hline 289 & 12 & Pessimistic scenario (20 min) & 5 & 161 \\
\hline & & Costs of the lab analysis & & \\
\hline 277 & NA & Base case & 50 & 158 \\
\hline 254 & -23 & CTG tarief & 27 & 135 \\
\hline 327 & 50 & Twice base case & 100 & 208 \\
\hline & & Costs related to review by pharmacist & & \\
\hline 277 & NA & Base case & 55 & 158 \\
\hline 236 & -41 & Optimistic scenario (5 min) & 14 & 117 \\
\hline 331 & 54 & Pessimistic scenario (40 min) & 109 & 213 \\
\hline & & Time related to contacting feed back to patient & & \\
\hline 277 & NA & Base case (6 min) & 16 & 158 \\
\hline 269 & -8 & Optimistic scenario (total $3 \mathrm{~min}$ ) & 8 & 150 \\
\hline 315 & 38 & Pessimistic scenario (20 min) & 54 & 196 \\
\hline & & All patient time is 'mantelzorg' time & & \\
\hline 277 & NA & Base case & 4 & 158 \\
\hline 222 & -55 & all time is 'mantelzorg' & 4 & 158 \\
\hline & & All patient time is 'productivity loss' & & \\
\hline 277 & NA & Base case & 4 & 158 \\
\hline 277 & 0 & all time is 'productivity loss' & 9 & 164 \\
\hline
\end{tabular}




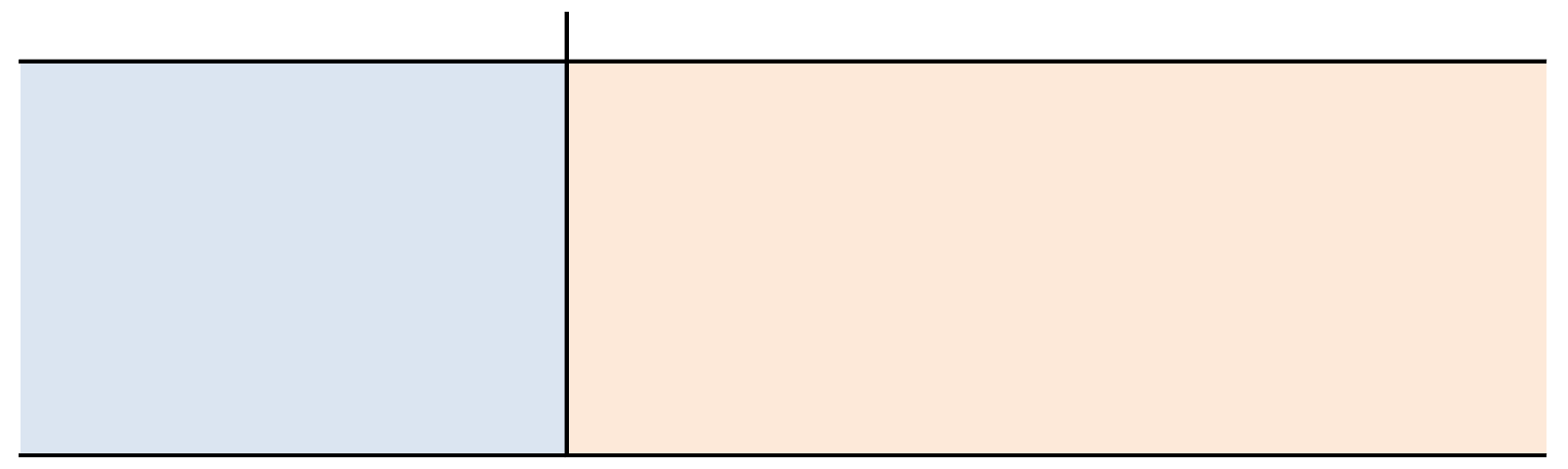




\section{, \\ Difference with base case}

NA

NA

NA

NA

NA

NA

NA

NA

NA

$-1$

2

NA

$-23$

50

NA

$-41$

54

NA

$-8$

38

NA

0

NA

6 
$\downarrow$ 
Schretlen k 


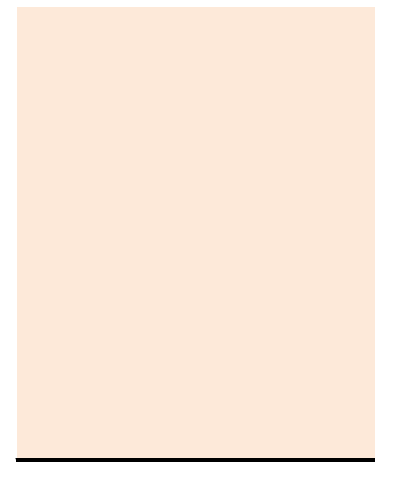


Handleiding voor kostenonderzoek. 8 sept2015. hst 5.1.2. 0.19 ct per km. 